FORMAÇÃO DE PROFISSIONAIS DA EDUCAÇÃO

\title{
O AGIR COMUNICATIVO NA EDUCAÇÃO COMO DISPOSITIVO E AUTORIDADE EPISTÊMICA À PRÁXIS TECNOLÓGICA*
}

\author{
Elaine $\operatorname{Conte}^{1}$ (D) \\ Adilson Cristiano Habowski ${ }^{1}$ (D)
}

\begin{abstract}
RESUMO: Ao considerar a importância da abertura à experiência comunicativa na educação e na sociedade hiperestimulada pelas tecnologias, o estudo de bases hermenêuticas objetiva repensar a práxis pedagógica, mobilizando, por meio de pesquisas habermasianas, as possibilidades de interconexóes formativas com as tecnologias digitais de informação e comunicação. Para tanto, Habermas traz questôes que denunciam as falsas fronteiras do conhecimento e os potenciais do agir comunicativo nas interfaces educacionais para resistir à razão técnica, à pedagogização, às simplificaçóes e visóes estreitas de mundo. Concluímos que a interdependência linguística pode renovar as formas de ensinar e de aprender geradas pelas tecnologias, abrindo canais reflexivos para superar narrativas vazias e monológicas.
\end{abstract}

Palavras-chave: Agir comunicativo. Tecnologias digitais. Educação.

\section{COMMUNiCATION ACTION IN EDUCATION AS A DEVICE AND EPISTEMIC AUTHORITY TO TECHNOLOGICAL PRAXIS}

\begin{abstract}
In considering the importance of openness to communicative experience in education and in a society hyperstimulated by technologies, the study of hermeneutical bases aims at rethinking pedagogical praxis, mobilizing, through Habermasian research, the possibilities of formative interconnections with digital information and communication technologies. For this purpose, Habermas brings up issues that report the false frontiers of knowledge and the potentials of communicative action in educational interfaces, to resist technical reason, pedagogisation, simplifications and narrow worldviews. We conclude that linguistic interdependence can renew the forms of teaching and learning generated by technologies, opening up reflective channels to overcome empty and monological narratives.
\end{abstract}

Keywords: Communicative action. Digital technologies. Education.

\footnotetext{
*Este artigo está vinculado ao projeto de pesquisa "Educação Permanente e Inclusão Tecnológica: rumo à democratizaçáo dos saberes", coordenado pela autora, tendo como agências fomentadoras - CNPq e FAPERGS. ${ }^{1}$ Universidade La Salle, Programa de Pós-Graduação em Educação. E-mails: elaine.conte@unilasalle.edu.br; adilsonhabowski@hotmail.com

DOI: 10.1590/ES0101-73302019193424
}

Educ. Soc., Campinas, v.40, e0193424, 2019 


\title{
EL ACTUAR COMUNICATIVO EN LA EDUCACIÓN COMO DISPOSITIVO Y AUTORIDAD EPISTÉMICA A LA PRAXIS TECNOLÓGICA
}

\begin{abstract}
RESUMEN: Al considerar la importancia de la apertura a la experiencia comunicativa en la educación y en la sociedad híper-estimulada por las tecnologías, el estudio de bases hermenéuticas objetiva repensar la praxis pedagógica, movilizando, por medio de investigaciones habermasianas, las posibilidades de interconexiones formativas con las tecnologías digitales de información y comunicación. Para tal, Habermas trae cuestiones que denuncian las falsas fronteras del conocimiento y los potenciales del actuar comunicativo en las interfaces educacionales para resistir a la razón técnica, a la pedagogización, a las simplificaciones y visiones estrechas de mundo. Concluimos que la interdependencia lingüística puede renovar las formas de enseñar y de aprender generadas por las tecnologías, abriendo canales reflexivos para superar narrativas vacías y monológicas.
\end{abstract}

Palabras clave: Actuar comunicativo. Tecnologías digitales. Educación.

\section{Considerações iniciais}

A

autoridade epistêmica na educação implica reflexão e liberdade cooperativa por meio da ação comunicativa, sendo uma das condiçóes para despertar aprendizagens sempre renovadas pelo reconhecimento intersubjetivo e pela resistência à instrumentalização das práticas cotidianas no exercício de descentração evolutiva das sociedades contemporâneas. $\mathrm{Na}$ tentativa de esclarecer as aporias da autoridade epistêmica ante a práxis tecnológica que centralizou a razão técnica e operacional do pensamento moderno, a problemática gira em torno de que talvez as máquinas educativas dispensem o professor de uma demanda das situaçóes humanas, permanecendo aquém do princípio civilizatório e de autoridade dialógica que ele representa por outorgar à tecnologia um lugar proeminente na vida do ser humano. Daí que tal reflexão permitirá desenvolver um trabalho interpretativo de mediação entre as necessidades da educação e as propostas emergentes, tendo como norte a seguinte problematização: quais elementos o agir comunicativo de Habermas oferece para refletirmos sobre as possibilidades de uma racionalidade aprendente e intrinsecamente pedagógica mediada pelas tecnologias digitais?

Adotamos como fio condutor para a análise a abordagem hermenêutica, que é voltada para a exploração e a compreensão de discursos, textos e das variadas produçóes humanas no mundo. Segundo Habermas (1994, p. 351), "o esforço her- 
menêutico almeja a apropriação de sentido, presente em cada momento uma voz silenciada que deve ser novamente despertada para a vida”. A busca pela humanização e inteligibilidade das relaçóes intersubjetivas implica o empenho não violento em busca da liberdade cooperativa (por meio das tecnologias digitais e de seu progresso ameaçador) e do diálogo com o diferente. $\mathrm{O}$ agir comunicativo na interdependência humana da relação digital converge para múltiplas interpretações cognitivas e expectativas normativas na práxis cotidiana, manifestando o desenvolvimento de uma nova racionalidade aprendente e questionadora em meio aos artefatos tecnológicos. Nesse contexto, a linguagem corrente se torna alicerce para a construção do conhecimento no mundo, uma vez que os debates educativos necessitam de uma atitude hermenêutica voltada para ensinar a compreensão, já que exige uma coordenação de açóes linguísticas dirigidas ao entendimento das questóes vigentes que partem dos contextos culturais e da realidade para avançar na radicalização do diálogo.

\section{Dialogando com Habermas...}

O sujeito só poderá existir e crescer em suas reflexóes no contato e mediação com o outro, que pode duvidar e discutir a respeito de tudo, em uma relação de diálogo aberto com os discursos contraditórios na práxis constitutiva (HABERMAS, 1994). É nessa perspectiva que o debate sobre a capacidade do agir comunicativo é uma demanda contemporânea, pois envolve uma relação de reciprocidade e abertura às diferenças do outro de forma interpeladora e na qual reside a comunicação. Nesse sentido, o encontro com o mundo do outro surge como potencial interpretativo e questionador das tecnologias digitais, que é uma faca de dois gumes: tanto pode vincular erros, alienaçóes e imprecisóes, quanto pode gerar uma relação político-social de resistência recíproca diante das injustiças sociais (pessoas que não conseguem estudar porque precisam trabalhar desde a infância) e de responsabilizar-se pelas próprias açóes na esfera pública e democrática dos saberes.

Habermas compreende que a razão unidimensional consiste na imperfeição dos meios e na confusão dos fins, pois é tomada de modo instrumental e solipsista, argumentando que somente uma racionalidade comunicativa e global poderia superar a perspectiva do sistema informativo do controle total causado pela overdose acrítica de informaçōes. Habermas (1990, p. 414) destaca que "o que está esgotado é o paradigma da filosofia da consciência", que será superado a partir do paradigma do entendimento recíproco num horizonte ambíguo de questóes abertas, de exercícios de estudos e de interesse de pesquisa com a alteridade. A crítica de fundo de Habermas parte da autocompreensão ocidental, definida pela relação dos sujeitos com o mundo de forma imperialista e objetivada nos interesses cognitivo-instrumental (dominada pelas regras do dinheiro e poder), de uma racionalidade voltada ao êxito e ao poder, desconsiderando a discussão crítica e o desenvolvimento humano e cultural como condição para a reconstrução coletiva de conhecimentos. 
O entendimento do sujeito em relação ao mundo somente pelo ponto de vista unidimensional da razão técnica provoca, conforme Habermas (2002a, p. 43), a "reificação e funcionalização de formas de vida e de relacionamento", em um entendimento objetivista da ciência e da técnica que monopoliza os processos de formaçáa por interesses de um mundo fixo, neutro e capitalista. Essa conjuntura suscitou críticas aos fundamentos da filosofia da consciência que compreende todo o conjunto do real a partir da dualidade sujeito-objeto, desconsiderando que todo conhecimento é posto em movimento por interesses. O esgotamento do paradigma da subjetividade (de uma consciência isenta de coerçáo) direciona uma guinada para uma racionalidade comunicativa, reflexiva, aprendente e global de uma práxis emancipatória dos que participam da comunicação. Habermas (1987) afirma que a racionalidade da ação ocorre por meio da dialética, pois é no processo de movimento histórico e epistemológico do movimento desvelado nos múltiplos sentidos e contradiçóes humanas do mundo da vida, que as açóes comunicativas são permanentemente renovadas e postas em xeque em meio à cultura da conexão. Assim, a discutibilidade provoca a "passagem para o paradigma do entendimento recíproco", para uma formação performativa de devir humanizador, mediante a qual a ação só pode ser do próprio sujeito que fala e se transforma em um ser cultural com o outro por meio do agir comunicativo (HABERMAS, 1990, p. 414). É por meio da problematicidade das questôes que estão em movimento na multiplicidade da práxis constitutiva de mundo que conseguiremos (re)aprender conforme as transformaçóes dialéticas, abrindo possibilidades às (re) criaçóes humanas com o outro e à circularidade hermenêutica para a transformação cultural e social.

Na obra Teoria do agir comunicativo, Habermas (2012) desenvolve a tese de uma reconstrução da teoria da sociedade e sua relação com mundo em uma perspectiva de corretivo da prática alienada pela reflexão, correspondendo a uma transformaçáo das práticas sociais pelas consequências que o saber opera no real. Nisso, apresenta três finalidades profundamente conexas, aperfeiçoando um conceito de racionalidade que ultrapasse a miragem subjetivista e racionalista, buscando a integridade do pensamento frente aos paliativos do ativismo prático de uma racionalidade sistêmica.

Com a teoria, Habermas (1990) traça uma mudança de direção rumo ao paradigma da linguagem, cujo intercâmbio analítico entre interlocutores é o exercício emancipatório do conhecimento na práxis social. O saber comunicativo supõe um procedimento de interação e uma abordagem performativa dos sujeitos como agentes capazes de fala e ação que saibam distinguir entre discurso esclarecido e institucionalização política desse discurso. Em Habermas (2003), é conferida a autoridade epistêmica para os sujeitos que falam com os outros no seio da comunidade comunicacional e trabalham cooperativamente. 
A racionalidade comunicativa se tornou possível com o advento da modernidade, que emancipou o homem do jugo da tradiçáo e da autoridade, e permitiu que ele próprio decidisse, sujeito unicamente à força do melhor argumento, que proposiçóes são ou não aceitáveis, na tríplice dimensão da verdade (mundo objetivo), da justiça (mundo social) e da veracidade (mundo subjetivo) (ROUANET, 2005, p. 14).

Esse intercâmbio comunicativo precisa estar apoiado na crítica do conhecimento de significação processual e na curiosidade epistemológica de perspectiva praxiológica, em que os envolvidos de uma circunstância argumentativa almejam alcançar o entendimento coletivo sem dispensar a dúvida para avaliar o modus operandi da sociedade. A partir de um longo processo formativo pautado na crítica, Habermas torna possível uma reconstrução dos saberes do mundo subjetivo, objetivo e social, entendendo a linguagem como modo de ação, contradição, paradoxo e dilema formativo da experiência humana, náo simplesmente como adaptação unidimensional e absoluta de uma autoridade alheia. Essa guinada de sentidos epistemológicos da linguagem como forma de expressão resulta na teoria do agir comunicativo, mediante a consideração da pragmática formal, tornando provável a restauração das condiçóes discursivas do conhecimento possível entre os sujeitos participantes.

A pragmática formal constitui uma epistemologia social de confluências e tensões que investiga as circunstâncias gerais do discurso universal e do entendimento presumível por intermédio de uma racionalidade mais ampla, ancorada na interdependência comunicativa e nas próprias contingências em que nos movemos e nos constituímos. Isto é, trata-se de uma racionalidade crítica do conhecimento com potencial para o mútuo entendimento, em uma tentativa de coordenar as ações entre falantes competentes em argumentações presentes em diferentes culturas (descentralização), contemplando a diversidade de discursos e leituras de mundo, assim como a solidariedade em múltiplas culturas e processos formativos. Numa compreensão pragmática, a linguagem tem seu entendimento como ação prática e política, ou seja, uma ação social e uma práxis participativa que traz à tona o processo firmado na intersubjetividade de um sujeito que reconhece o outro (momento da unidade na diversidade) em relação ao mundo. Para Habermas (2002b, p. 9), “a função da pragmática universal é identificar e reconstruir condiçóes universais de possível compreensão mútua”, da diversidade como uma relação entre sujeitos do agir comunicativo. Trata-se de uma experiência de restaurar e manifestar as convicçóes necessárias à construção da vida humana para além da objetividade funcional do agir instrumental, ou seja, reconstruindo as condiçóes gerais de fala, que são basilares para o entendimento intersubjetivo.

Todo esse procedimento para a sensibilização linguística visa chegar a um acordo justo que atenda as condiçóes de uma formação na própria ação comunicati- 
va que permita pensar os processos de trabalho como necessidades naturais da vida e da evoluçáo humana. Assim, a intercomunicação pode ser obtida por meio da educação, visto que exige liberdade cooperativa e interdependência como forma de autorrealização (autodesenvolver-se) mútua. Para Habermas (1982), uma forma de vida esclerosada na abstraçáo tem, na aversáo ao outro, a experiência da alienaçáo de si mesmo. Para chegarmos a um acordo sobre algo no mundo é necessário ouvir a voz do outro participante, o que implica não impor ao outro de forma intencional ou coercitiva uma estratégia de açáo que o impeça de aperfeiçoar as suas próprias deliberaçóes, endereçando também a si mesmo a crítica ideológica. Ou seja, todo acordo alcançado comunicativamente se baseia em experiências sociais de liberdade, confiança e reconhecimento mútuo na autorreflexão do saber coletivo. O sentido da comunicação é construir novas significações por meio da interação e da ampliação interdisciplinar de pesquisa e interpretação do mundo.

Toda postura comunicativa que visa o entendimento necessitará oferecer pretensões de legitimidade que possam ser justificáveis ao melhoramento de nossas condiçôes de vida. A sua lógica também tem o intuito de comunicar algo verdadeiro e incorruptível à medida que observa as normas e valores vigentes de modo que falante e ouvinte possam se entender mutuamente sem precisar desprezar o argumento do outro. Na incompletude e relatividade do nosso conhecimento, a busca de entendimento é a condição de legitimidade das pretensóes, do mesmo modo que a justificação das aspiraçóes apresentadas. Assim, "o significado da validade reside no seu valor em termos de reconhecimento" (HABERMAS, 2002b, p. 15). Conforme Habermas (2002b, p. 47), "a teoria dos atos de fala defende a existência de uma competência de regras comunicativas correspondentes", que proporciona aos envolvidos o uso de locuçóes gramaticais capazes de satisfazer as condições à compreensão e à própria emancipação da relação. Essa capacidade apresentaria um modo universal suscetível de crítica e de ser posta em dúvida, considerando o contexto cultural da declaraçáo linguística. Dessa forma, compreendemos que todo o processo de conhecimento é discursivo, sendo habilitados linguisticamente os sujeitos capazes de preencher os pré-requisitos gramaticais de compreensibilidade da linguagem em termos significativos (reais) e denotativos (individuais). De acordo com Habermas (1982), precisamos tomar cuidado para não nos submetermos à lógica perversa do mercado que, no caso dos produtos culturais, tende ao nivelamento por baixo e à banalização, especialmente da comunicação.

Habermas (1982) reconstrói, a partir da proposição popperiana, o conceito tríplice de mundo como forma de julgar, educar e decidir. Assim, temos o mundo objetivo definido a partir do mundo físico ou do estado das coisas existentes; o mundo social ou normativo se refere às normas sociais e culturais sob as quais atuamos e o mundo subjetivo se revela na autenticidade e veracidade do mundo interno (estético-expressivo) dos sujeitos. Isso significa que os processos de aprendizagem da humanidade dependem de uma racionalidade global e integradora dos mundos objetivo, social e subjetivo para viabilizar a difusão do progresso 
cognitivo de diferentes atos de fala projetados, atos (auto)regulativos de aprendizagem e atos expressivos de percepção e gosto irrevogável.

Com o mundo da vida tomado globalmente pela reprodução eletrônica do agir comunicativo, as mudanças políticas e socioculturais passam por reconfiguraçóes nos movimentos e processos de democratização social. Habermas (2012, p. 63) observa que os meios de comunicação transformaram a presença física num processo de "ubiquidade", ou seja, de desdiferenciação, de desenraizamento e de desestruturação da vida diante de uma espécie de impotência sistêmica e individualizaçâo dos projetos eletrônicos que atingem a multiplicidade da vida social. Para Habermas (2015, p. 93), as redes comunicativas, complexas, digitais e os processos democráticos encontram-se em "liqueficação comunicativa da política" e das formas de vida pela interdependência dos desenvolvimentos da "sociedade da informação", da "sociedade em rede" e da "sociedade dos medias" - que conduzem revoluçóes dos métodos de transmissão eletrônicos.

Diante da indisponibilidade do outro pela confusão e desorientação comunicativa dos processos eletrônicos, o agir pedagógico acaba sendo confrontado com os limites das próprias comunicaçóes demasiado abstratas e desacopladas de relações e interligaçôes discursivas, causando a degeneração das pretensōes de validade comunicativa a meras opinióes, sujeitas à regulação do mercado. No entanto, a internet potencializou a multiculturalidade e redesenhou as fronteiras do conhecimento porque no mundo virtual da comunicação se cria uma ciberdemocracia (rede democrática) igualitária nas formas de expressão e proferimento.

Afinal, a internet não produziu apenas navegadores curiosos, mas reavivou igualmente a figura historicamente submersa de um público igualitário de participantes de conversão e parceiros de correspondência que escrevem e leem. Por outro, é apenas relativamente a um contexto específico que a comunicação eletrônica pode reivindicar méritos democráticos: ela mina a censura de regimes autoritários que tentam controlar e reprimir as opiniōes públicas espontâneas (HABERMAS, 2015, p. 97).

Ressalta-se que, para Habermas, a capacidade comunicativa é uma característica do ser humano, sendo uma competência universal própria da vida, instável, transitória, dialética, de questóes abertas e sempre renováveis. $\mathrm{O}$ entendimento coletivo de uma prática comunicativa é plausível por intermédio de atos e de fala, que são aspiraçóes de legitimidade que podem ser aceitas ou não pelo interlocutor, possuindo na capacidade ilocucionária o componente catalisador da compreensão.

Cabe destacar que todo ato discursivo possui uma dualidade de significaçóes que tanto aperfeiçoam a dimensáo linguística constituinte da fala e dos procedimentos de comunicação quanto tem um sentido institucional, que corre o risco de estagnação ao divulgar e reproduzir a linguagem social e cultural a par- 
tir de interesses orientadores do conhecimento, que podem ser concebidos como mero instrumento de adaptação. A capacidade formativa de um ato de fala é articulada à experiência da reflexão, em uma relaçáo interpessoal entre os falantes, sendo bem-sucedido o processo comunicativo comprometido com a intersubjetividade de uma comunicação semântica com o outro. No caso das conjunturas, em que os atos de fala são faculdades interdependentes, o ouvinte "poderá talvez confiar na força vinculativa de uma norma de ação estabelecida" (HABERMAS, 2002b, p. 93) em que modificará o sustentáculo de justificação das pretensōes de legitimidade proferidas para as condutas constituídas e reconhecidas por determinada instituição. É a partir de significados reivindicados pela experiência comunicativa entre falantes e da aspiração de legitimidade firmada no ato de fala que Habermas (2002b, p. 95) diz que tal conteúdo "é definido por uma forma específica de apelar a uma mesma pretensão de validade universal e tematicamente salientada”, o comprometimento apresentado será capaz de ser manifestado na relação compreensiva.

Conforme Habermas (2002b, p. 92), "a pressuposição essencial para o sucesso de um ato ilocutório consiste na assunção por parte do falante de um compromisso específico (Engagement), de forma a que o ouvinte possa confiar nele". Com esse entendimento, compreendemos que seja qual for a proposição do falante que almeje se colocar em um estágio de desenvolvimento e respeito pela palavra do outro, necessitará pressupor que o comprometimento do falante dispõe de "um conteúdo específico e que o mesmo está sinceramente disposto a assumi-lo" e, assim sendo, "a força ilocutória de um ato de fala aceitável reside no fato de poder levar um ouvinte a confiar nas obrigaçóes típicas dos atos de fala do falante" (HABERMAS, 2002b, p. 92-93). "Em última análise, o falante pode influenciar ilocutoriamente o ouvinte e vice-versa, uma vez que as obrigações típicas dos atos de fala estão ligadas a pretensōes de validade cognitivamente testáveis" (HABERMAS, 2002b, p. 94).

\section{$\mathrm{O}$ agir comunicativo e as tecnologias digitais}

Os processos de ensino e aprendizagem no contexto das tecnologias digitais confluem para elucidar as fragilidades do processo comunicativo no sentido de estabelecer novas relaçôes da autoridade epistêmica entre os conteúdos culturais e os modos de interação, visando atualização e problematização dos conceitos e suas relaçóes. Há, portanto, que se compreender a autoridade nesse cenário tecnológico digital para o desenvolvimento dos processos formativos de bases dialógicas sem o autoritarismo de um sujeito que tem a última palavra, convidando para indagaçóes sobre os conhecimentos que estão se (re)configurando com as ressonâncias das tecnologias digitais. Tais perspectivas compóem as dimensões básicas da interação e da práxis pedagógica que não se limitam a consideraçóes objetivas 
e resolutivas mas abrem outros sentidos articulados pela capacidade de reflexão, já que o conhecimento é resultado dos tensionamentos que movimentam as percepçóes dos sujeitos como forma de resistir aos dispositivos de poder coercitivo pela autoridade. Dessa forma, a busca de sentido das tecnologias na educação é um esforço cujo propósito é problematizar também a questáo da autoridade epistêmica, que é uma condiçấo histórica e cultural de ensinar e de aprender em uma relação de interdependência comunicativa.

Na perspectiva de Habermas (2006), as biotecnologias e as cibertecnologias não conseguem controlar o comportamento humano pois esse orienta as razóes desenvolvidas pela linguagem, que não se deixa levar em sua complexidade por uma vontade de dominação tecnocrática. O saber das tecnologias e dos discursos pungentes influencia a formaçấo da identidade nas redes simbólicas do espaço público da esfera autonomizada (poder de disposição tecnocientífico) e nas esferas humanistas dos diversos campos sociais. Nesse movimento, a comunicação por meio das tecnologias é enfraquecida no mundo hiperconectado e mergulhado em (des)informaçôes, fragmentando a possibilidade de um consenso social pois as discordâncias são anuladas e deletadas facilmente e um argumento é substituído por outro de forma irrefletida e inquestionada, gerando um subdesenvolvido sentido pedagógico ancorado na reflexividade. A educação engessada não permite realizar a guinada reconstrutiva dos saberes, por isso que as tecnologias digitais podem ser provocadoras de transformaçóes nos modos de aprender e agir comunicativamente com os outros, alterando a autoridade do educador. Tais mudanças se refletem na educação contemporânea pela crise dos modelos de ensino silenciadores, técnicos, neutros, permissivos e com barreiras em relação ao mundo e a nós mesmos. O engajamento social e comunicativo das tecnologias digitais desafia e desperta a educação para rever a sua tecnicidade, característica comportamentalista do estímulo-resposta, de identificação com a neutralidade tecnocientífica.

Operando com conceitos oriundos de um diálogo crítico com a atualidade, o outro sugere um debate diverso e plural, mesmo que isso envolva riscos e inclusão de diferentes formas hipertextuais de aprendizagem, exigindo a necessidade de aprender com o outro como forma de criaçáo de novos sentidos em um movimento de ações de sentido formativo e reconstrutivo às produções humanas. Assim, a intersubjetividade "conjuga a perspectiva de cada um com a perspectiva de todos", que pode ser constituída em "um discurso ampliado universalmente, no qual todos os possivelmente envolvidos possam participar e tomar posiçẫo com argumentos numa postura hipotética em vista das pretensóes à validade" (HABERMAS, 1989, p. 299). Nesse viés, Habermas se esforça para superar a relação autonomizada, solitária, instrumental e dominadora (sujeito-objeto) por uma relação intersubjetiva (livre de domínio) com o outro. Nesse agir comunicativo, os envolvidos "não estão orientados primeiramente para o seu próprio sucesso individual, eles buscam seus objetivos individuais respeitando a condição de que podem harmonizar seus planos de ação" (HABERMAS, 1994, p. 285-286). 
A linguagem, enquanto mediação e práxis do sujeito no mundo, é essencial para a ampliação de horizontes culturais e de entendimento mútuo ao diálogo de integração social, em casos onde a comunicação fica perturbada. Conforme Habermas (2009, p. 67), "uma língua não é propriedade privada de um indivíduo, mas cria um contexto de sentido intersubjetivamente partilhado, corporificado em expressões culturais e práticas sociais". O conhecimento está enraizado na tradição (poder social) e nas condiçóes contingentes, por isso requer abertura à alteridade e às múltiplas formas de aprender em meio às mudanças tecnológicas, uma vez que a construção do saber só estará consolidada pela participação ativa (autorreflexão) e formaçáo democrática compreendida como um enriquecimento mútuo, em um esforço constante de renovação. O entendimento de Habermas (2009) abre horizontes para enfrentar as fortes transformações trazidas pela legitimação das tecnologias digitais e pela reestruturação produtiva dos rumos da sociedade em um viés educacional de contextos diversificados de ação, desenvolvendo um potencial de resistência aos condicionamentos e patologias sociais existentes.

A intersubjetividade é permeada por tensões, servindo como ponto de partida para a constituição do sujeito (falante e participante) e o elemento indispensável na tessitura da vida social que valoriza as diferentes experiências e conecta os sujeitos em uma racionalidade comunicativa processual, global, sem a qual não seria possível o entendimento, a utopia, a mudança de atitude reflexiva. A compulsão repetitiva desenvolvida de forma auxiliar com fins didáticos na educação gera a tecnificação e massificação de atos de fala locucionários (ilustrado na figura do professor que apenas explica e transmite a matéria) e perlocucionários (de professores que visam convencer por meio de perguntas e respostas prontas). Os sujeitos só conseguem ultrapassar a subjetividade que incide nos seus interesses particulares cooperando em um processo intersubjetivo que lhes permite alargar o horizonte de compreensóes pela problematização e reflexão com o outro, como práxis de reconstrução própria do próprio conhecimento ilimitado de interpretação.

Posto que as tecnologias digitais venham nos proporcionando outros horizontes e visóes de mundo, que a cada instante se revelam multifacetadas, dinâmicas, ambíguas e fascinantes, precisamos nos posicionar diante dessa realidade com o necessário engajamento social e político, especialmente no que tange ao acoplamento que as tecnologias provocam no intercâmbio de visóes de mundo. Assim, se a possibilidade criadora do agir humano habita na linguagem social, nas contradiçóes e tensóes discursivas, "no quadro de um processo de entendimento mútuo - virtual ou atual — não há nada que permita decidir a priori quem tem de aprender de quem" (HABERMAS, 2003, p. 43), pois a construção do conhecimento reclama o desenvolvimento de novas formas de comunicação no ensino, para não reproduzirmos pseudocomunicaçóes de espectadores deslumbrados.

Zuin (2017) chama a atenção para o problema da autoridade do professor na era da concentração dispersa, revelando os desafios provocados pela invasão dos 
meios eletrônicos na prática educativa, que restringe o pensar e as interlocuçóes no processo pedagógico, causando a improvisação e a precarização das relaçóes humanas, notadamente porque sem autoridade e abertura dialógica não se faz educação. A revolução tecnológica vivenciada na educação para assegurar a autoridade do educador em sala de aula em meio aos artefatos tecnológicos é algo desafiador, visto que passa pelos mecanismos de interação, hiperestimulação e desatenção cuja interdependência com a área das tecnologias digitais coloca as potencialidades das açóes pedagógicas em xeque, tornando os professores equilibristas do saber em um jogo que interconecta conhecimentos e democratiza informaçóes com o outro. A autoridade do educador pertence ao mundo da formação cultural, cujo processo está vinculado às ideias de ensino, aprendizagem e competência (inter)pessoal, bem como a buscas, dúvidas e inquietações, pois surge do diálogo no cenário das tecnologias digitais. Os sistemas estáveis de disciplina, limite e (co)autoria recebem novos sentidos nas dimensóes do ensinar a pensar e do aprender a agir comunicativamente nos contextos e contradiçôes sociais da sociabilidade em esferas de interação educacional. Isso implica autoridade epistemológica em outros espaços de legitimação, para além do controle ou desintegração da educação, no sentido de formar as novas gerações com mais vontade e autonomia para problematizar a práxis socioeducacional e digital, garantindo as condiçóes para que todos possam se pronunciar e participar das açóes coletivas.

O agir comunicativo na educação se torna fundamental, já que é o campo de interações para a conversação com o diferente e o compartilhar de conhecimentos para compreender a sua complexidade nos processos formativos. Por isso, precisa fazer uso das tecnologias sob um olhar crítico-reflexivo para romper com a construção de um pensamento excludente e uniformizador, para ir contra as legitimaçóes de discursos ideológicos, para a emancipação humana nas tecnologias em que coexiste a liberdade de expressão e de comunicação enquanto luta pelo reconhecimento (HONNETH, 2003). Mas fazer frente à homogeneização cultural e resistir aos modismos uniformizados de ver o outro, viver e pensar o mundo que são veiculados pelas tecnologias, são desafios para a educação. Sabemos que a partir desse desafio acontece a valorização da intersubjetividade enquanto lócus locucinário. A ação comunicativa possibilita não apenas a interação entre os sujeitos, mas principalmente que os sujeitos melhorem sua comunicação com as tecnologias e com os outros. As possibilidades tecnológicas incorporadas se tornam aliadas da educação, em que falantes e ouvintes são os protagonistas para o estabelecimento de relaçóes interpessoais comunicando os conhecimentos e as experiências de vida, libertando-se dos domínios e das instrumentalizações técnicas para prosseguir nas mudanças sociais por meio da consciência crítica proporcionada pelo agir comunicativo.

Tendencialmente, os sistemas educativos têm assumido a inserção das tecnologias em sala de aula como algo que qualifica os processos de ensino, cujas relações estabelecidas são simpáticas à propagação de belos equipamentos, causando um excesso de (des)informação e disciplinas atravessadas, chegando até a negligenciar as operaçóes interpretativas dos sujeitos. Por isso, surgem críticas aos 
projetos de aprendizagem virtual assentadas no argumento de que a internet facilmente induz à cópia e à desinformação e subestima o professor, a participação democrática, o compromisso relacional e as reflexóes nessa realidade. $\mathrm{Na}$ tendência técnica e operacional, as instituiçóes de ensino esquecem que os artefatos tecnológicos funcionam de fora para dentro, armazenam e processam informaçóes, mas ainda não conseguem interpretar e reconstruir conhecimentos em relação dialógica com as diversas formas de vida.

A tecnologia não é algo neutro sendo possível, no ciberespaço, estudar em grupo sem sair de casa, na experiência divertida da presença virtual, assim como acessar diversas informações que podem ser visualizadas à distância, colocando em cheque nossos próprios conhecimentos. Se essa suposta prática instrumentalizadora e destituída de significação não existe apenas no mundo virtual e se estende a todos os âmbitos da vida e da educação, como dar visibilidade para acolher o outro na dimensão escolar e atribuir sentido às tecnologias digitais em meio à tentativa de homogeneização das diferenças humanas?

Tudo indica que a aprendizagem do agir comunicativo passa também pela abertura às tecnologias, ao diálogo com as diferenças, à crítica e à reconstrução de argumentos, visto que surge como chance de pesquisa e elaboraçáo inovadora de aprendizagens reconstrutivas. $\mathrm{Na}$ teoria do agir comunicativo de Habermas, o saber é o resultado da discussão social que pode atingir um consenso - melhor argumento extraído da condição de um debate sem coerção. Nessa direção, a educação tem a responsabilidade de desenvolver a capacidade argumentativa para aprender, formar e formar-se, de modo reflexivo e transformador, seja no que tange ao mundo atual ou virtual. Para que exista diálogo entre os interlocutores que buscam alcançar o consenso de algo no mundo, é necessário a comunicação com alteridade, indispensável para a obtenção do consenso e para a revisão constante das posiçóes culturais e dos saberes, implicando em um compromisso constante e investigativo das práticas sociais.

Os elementos da constituição do mundo integram as diversas culturas e suas linguagens, reproduzindo-se pelo agir comunicativo, originando princípios de raciocínio, de atitude e de construção da experiência social aprendente. Esse agir comunicativo, em uma perspectiva de práxis comunicativa cotidiana, é o modo do qual a cultura materializada "em objetos utilitários e tecnologias, em palavras e teorias, em livros e documentos, etc., tal como o faz nas ações" (HABERMAS, 2002b, p. 141), a sociedade e as estruturas de individualidade, originalidade e criatividade se ampliam e se reproduzem.

Cabe destacar que esses procedimentos (entendimento, coordenação da ação e socialização) são representativos e estruturados, possuindo na linguagem cotidiana o indicador comum a partir do qual se refletem, se conectam e interagem comunicativamente. A linguagem é o modo no qual os sujeitos podem se entender acerca de algo na sociedade, orientar suas próprias açôes, reflexôes e condutas vislum- 
brando processos evolutivos de aprendizagem. Por meio do discurso e por intermédio da aprendizagem se desenrola a possibilidade de reconstruçáo dos conhecimentos culturais acerca da sociedade objetiva, técnico-instrumental, dos saberes do mundo social compreendidos como éticos e políticos e dos saberes acerca de cada ser em sua autenticidade e diversidade, que são os aspectos estético-expressivo e prático-moral.

Segundo Habermas (2002b, p. 142), "mesmo os sistemas de ação que são altamente especializados na reproduçấo cultural (escola), ou integração social (o direito) ou a socialização (família) não operam com base em distinções rígidas", mas de uma perspectiva comum de estar no mundo intersubjetivamente compartilhado e estruturado. A partir dessa conjuntura, que é simbolicamente estruturada do mundo da vida, esses três procedimentos potencializam-se "entrelaçados entre si de uma forma equiprimordial” (HABERMAS, 2002b, p. 142). Nesse sentido, o agir comunicativo de Habermas oferece à educação pressupostos para a reconstrução de relaçôes interpessoais, uma vez que não é possível conceber um desenvolvimento cognitivo distanciado das interaçóes e das trocas de conhecimentos. Freire (2001, p. 67) pensa a educação como um ato político, uma vez que a comunicação "implica uma reciprocidade que não pode ser corrompida". Essa conversação é imprescindível, afinal "a educação é comunicação, é diálogo, na medida em que não é a transferência de saber, mas um encontro de sujeitos interlocutores que buscam a significação dos significados" (FREIRE, 2001, p. 69).

Enquanto dispositivo pedagógico, o ambiente virtual de aprendizagem com a utilização de diversos recursos pode estar voltado náo apenas para a democratizaçáo e o fácil acesso ao ensino, mas, sobretudo, para possibilitar o (re) conhecimento da capacidade de diálogo e do agir coletivo dos implicados nessa construção de aprendizagem, partindo da noção de educação articulada com a vida para a transformaçáo social. Assim, o ambiente virtual de aprendizagem pode ser importante para uma concepçáo reconstrutiva da aprendizagem e de (re) integração para um pensar coletivo. Apontamos que o ambiente virtual e a tecnointeraçáo proposta em si não são suficientes, pois podem acarretar o tecnicismo curricular e a manutençáo do controle social — na contramáo de uma educação democrática e emancipatória. Realizar experiências de responsabilidade pelo outro e pelo mundo, por meio de atos de criaçáo educativos, gera reconhecimento e abertura à nova episteme que brota da realidade na ampliação do diálogo com as diferenças, enquanto amadurecimento conjunto.

A utilização dos recursos tecnológicos em prol de melhor formação pessoal, social e política é uma realidade ainda distante, necessitando esforços de pesquisas, sobretudo no contexto escolar, visto que persistem discursos e práticas antagônicas, que vão desde domínios e pressóes psicológicas e ideológicas no ciberespaço exercidos por uma hierarquia de poderes, até o reconhecimento das tecnologias como potencias para um agir coletivo para a emancipação humana. Freire (2006) observa que a capacidade de diálogo é a abertura à inquietaçáo e à curiosidade epistemológica de aprender 
e evoluir em um viés de alteridade, indo além da uniformização ou homogeneização alienadora de saberes "porque os sujeitos dialógicos não apenas conservam sua identidade, mas a defendem e assim crescem um com o outro. O diálogo, por isso mesmo, não nivela, não reduz um ao outro. Nem é favor que um faz ao outro" (FREIRE, 2006, p. 118). Para Freire, não existe emancipaçáo individual, de um sujeito solitário, arbitrário e dominado por particularismos, visto que a dimensão da emancipação só tem sentido e validade na realização coletiva. Com isso, alteram-se os paradigmas conservadores de ensino articulados com as tecnologias, das hierarquias e autoritarismos dos processos de ensino e de aprendizagem que obedecem à simples reprodução mecanizada e manipuladora de conteúdos. Isto posto,

o modo humano de utilizá-la é que poderá modificar o homem, ao mesmo tempo modificando a própria informação. [...] A tecnologia não pode ser por si mesma fator revolucionário pela simples razão de estar sempre em modificação e consistir na introduçáo de puras mediaçóes que irão criar condiçóes novas para o desempenho da atividade social dos homens (PINTO, 2005, p. 671-672).

Trata-se de uma noção dialética de mediação do papel, valor e limites da tecnologia no campo educativo, que engendra a situação conjunta da ação de estranhamento e choque com um agir isolado e antidialógico para uma transformação dos contextos sociais de dominação que acontecem a partir das relações solitárias e competitivas da racionalidade capitalista a que obedecem. Podemos dizer que os limites dos usos das linguagens projetadas pelas tecnologias digitais denotam os limites de nossos mundos, de nossos contextos, embora não exista uma forma básica da linguagem, mas uma pluralidade. Assim, novos jogos de linguagem surgem (outros desaparecem) como algo vivo, dinâmico, que só pode ser entendido a partir das relaçôes e da integração com as formas de vida.

Esses pensadores reacendem a necessidade de colocar em questão a atualidade manifestada na incapacidade para as interaçôes em uma sociedade do cansaço, que privilegia um viver subjetivista, hiperacelerado, desorientado e afastado do cotidiano pelo mundo de abstraçóes que as tecnologias reforçam. Conforme Freire (2001), a alternativa está na possibilidade do diálogo aberto, superando as situações desiguais entre opressor e oprimido, e na recuperação da complexidade humana por meio do aprender cooperativo, aventureiro e predisposto à mudança e aceitação das diferenças. A ação comunicativa precisa formar sujeitos livres e protagonistas para promover, além do mútuo entendimento, a (re)construção da educação enquanto processo progressivo, dinâmico e interativo, para ampliar as capacidades individuais e coletivas de reconhecimento humano e cultural. A capacidade do aprender na sociedade da informação pode gerar novas práticas sociais se a mudança iniciar pelo diálogo que corrói a instrumentalização técnica e de poder quando é empreendida por todos em um contexto de convivência reflexiva e mútua, aberta ao exercício de (re)conhecer e reinventar o mundo. 


\section{Considerações finais}

Levando em consideração os elementos apresentados até aqui, concluímos que Habermas converge para o reconhecimento humano perante as tematizaçōes da virtualidade ilimitada e em conflitos insolúveis, rumo à superação da alienação de tendências solipsistas de formação, lançando um desafio aos processos de aprendizagem na vida social e mostrando que a racionalidade pode ser reconstruída na aprendizagem solidária e participativa na ação pedagógica. A autoridade pedagógica passa a ser a forma como os sujeitos capazes de comunicação empregam o conhecimento tecnológico no mundo. Habermas oferece-nos, assim, importantes pistas para pensarmos a educação pautada na racionalidade aprendente e nas situaçóes pedagógicas do agir no mundo, com os outros na práxis profissional, abrindo perspectivas que tendem a superar as orientaçóes descoordenadas que alienam a formação pois não exigem a mediação pela linguagem relacionada às tematizaçóes didáticas. A instituição de ensino, nesse sentido, precisa fornecer subsídios para a (re)elaboração argumentativa do conhecimento frente aos meios tecnológicos para iniciar um diálogo de mudança que corrói a instrumentalização técnica e de poder quando é empreendida por todos, num contexto relacional, reflexivo, questionador e aberto ao exercício de crítica e reinvenção de um mundo democrático.

O movimento de problematização epistêmica e de contestação ao uso desmedido das tecnologias digitais pode promover outros acessos e sentidos comunicativos, indo além da neutralidade dos interesses tecnicistas, potencializando as ações vitais de compreensão mútua e as condições para (re)conhecer e (co)participar das pluralidades. É importante pensar e agir com as tecnologias quando se pretende facilitar atos de reconstrução pautados no diálogo e na compreensáo de sentido dos eventos do mundo para estimular a curiosidade e os processos de aprendizagem. A ação pedagógica de apreensão de sentido com as tecnologias digitais não está excluída de cognoscibilidade e do respeito pelas ideias e conhecimentos dos outros, pois o exercício da autoridade epistêmica acontece na experiência da comunicação humana, da ação intersubjetiva no contexto societário e da (re)construção coletiva. Torna-se necessário mantermos a vigilância crítica sobre as mudanças tecnológicas que decorrem de novas experiências sociais e do fluxo ininterrupto de informaçóes. Enquanto perspectivas às tecnologias digitais, o estudo nos revela que não há verdadeira construção do conhecimento sem a curiosidade que nos move diante do mundo, onde podemos reaprender com os outros como potência criadora de novos sentidos e resistências críticas às condiçôes materiais, econômicas, sociais, políticas, culturais e ideológicas que parecem obstáculos ao cumprimento de nossa tarefa pedagógica de melhorar o mundo, tendo em vista uma ação comunicativa por meio das aprendizagens sociais. 


\section{Referências}

FREIRE, P. A Educaçáo na Cidade. 5. ed. São Paulo: Cortez, 2001.

FREIRE, P. Extensáo ou Comunicaçáo? 11. ed. Rio de Janeiro: Paz e Terra, 2006.

HABERMAS, J. Conhecimento e Interesse. Rio de Janeiro: Zahar, 1982.

HABERMAS, J. Consciência Moral e Agir Comunicativo. Rio de Janeiro: Tempo Brasileiro, 2003.

HABERMAS, J.Dialética e Hermenêutica. Porto Alegre: L\&PM, 1987.

HABERMAS, J.O Discurso Filosófico da Modernidade. Lisboa: Dom Quixote, 1990.

HABERMAS, J.O Futuro da Natureza Humana: A Caminho de uma Eugenia Liberal? Tradução de Maria Benedita Bettencourt. Lisboa: Almedina, 2006.

HABERMAS, J.Para o Uso Pragmático e Ético da Razáo Prática. Texto apresentado na Conferência da USP. São Paulo: USP, 1989.

HABERMAS, J.Pensamento pós-metafísico: estudos filosóficos. 2. ed. Rio de Janeiro: Tempo Brasileiro, 2002a.

HABERMAS, J.Racionalidade e comunicaçáo. Lisboa: 70, 2002 b.

HABERMAS, J.Técnica e ciência como ideologia. Tradução de Artur Morão. Lisboa: Dom Quixote, 1994.

HABERMAS, J.Teoria do agir comunicativo: racionalidade da ação e racionalização social. São Paulo: Martins Fontes, 2012.

HABERMAS, J.Teoria Política: Obras escolhidas de Jürgen Habermas. Lisboa: 70, 2015. v. 4.

HABERMAS, J.Verdade e Justificaçáo: ensaios filosóficos. 2. ed. Tradução de Milton Camargo Mota. São Paulo: Loyola, 2009.

HONNETH, A. Luta por reconhecimento: a gramática moral dos conflitos sociais. Tradução de Luiz Repa. São Paulo: 34, 2003.

PINTO, Á. V. O conceito de tecnologia. Rio de Janeiro: Contraponto, 2005. v. 2.

ROUANET, S. P. As razóes do Iluminismo. 2. ed. São Paulo: Companhia das Letras, 2005.

ZUIN, A. Á. S. Cyberbullying contra professores: dilemas da autoridade dos educadores na era da concentração dispersa. São Paulo: Ediçóes Loyola, 2017.

Recebido em 26 de março de 2018.

Aceito em 16 de agosto de 2018. 